\title{
Evidences of Spatiotemporal Climate Change and its Mitigation in Ethiopia
}

\section{Abbadi Girmay Reda*}

Director and senior researcher, Tigray Agricultural Research Institute (TARI), Pob: 492, Mekelle, Ethiopia

"Corresponding author: Abbadi Girmay Reda, Director and senior researcher, Tigray Agricultural Research Institute (TARI), Pob: 492, Mekelle, Ethiopia, Tel: +251-914-733075; E-mail: abbadigirmayreda@gmail.com

Rec date: Dec 14, 2015; Acc date: Jan 01, 2016; Pub date: Jan 09, 2016

Copyright: (C) 2016 Abbadi Girmay R, et al. This is an open-access article distributed under the terms of the Creative Commons Attribution License, which permits unrestricted use, distribution, and reproduction in any medium, provided the original author and source are credited.

Abstract
The change detection at country level was unidirectional trend analysis between two time periods of 1946 and
2006 . Temperature shows increasing trend but rainfall shows fluctuation. Point analysis of climate data at local level
(1980-2010), Mekelle town, Northern Ethiopia, one of the semi-arid areas, showed that minimum temperature for the
months of October through January had an increasing trend while maximum temperature for the hot season (April-
June) and annual rainfall had no significant trend and were inconsistent. Region-specific detailed and seasonal
climate studies are needed and to be integrated with local context of agriculture, livelihoods, forecasts and
development plans for effective Early Warning Systems to utilize climate potentials and minimize natural disasters.
This study serves as a milestone for further detailed agroclimatic and sector based analysis of spatio-temporal
climate change patterns, impact assessment and adaptation and mitigation strategies. Massive sustainable local
community based natural resource management efforts have been undertaken and there had been lots of success
stories in the last 25 years. SLM practices constitute key adaptation and mitigation measures by resulting in reduced
soil erosion, improved water retention, and improved land productivity. Rainfall generally shows declining trend with
exception to Northern Region for the period of 1946 to 2006 . Moist areas of Western and South Western Ethiopia
are showing negative trend of rainfall which indicates that their forest covers have been deteriorating through time.
However, the drier Northern Ethiopia region area shows positive (upward) trends owing to massive environmental
rehabilitation and restoration of degraded lands into productive lands in the last 25 years. The public investment in
Northern Ethiopia region on environmental rehabilitation has resulted in rehabilitated environment and contributed to
reversing adverse effects of climate change. These local actions taken as adaptation and mitigation strategies
against global warming should be encouraged, globally recognized, and rewarded.

Keywords: Ethiopia; Climate change detection; GIS; Spatiotemporal analysis; SLM; Mitigation

\section{Introduction}

Whilst land degradation has already taken and continues to take its toll, climate change poses another real challenge to Ethiopian agriculture. Seasonal and inter-annual rainfall variability has increased and temperature shows an increasing trend. Ethiopia is already suffering from variability and extremes of climate $[1,2]$. World Bank (2006) asserts that rainfall variability costs the Ethiopian economy $38 \%$ of its potential growth rate. Net revenue per hectare will be reduced by USD 177.62 and 464.71 consequent to a unit increase in temperature during summer and winter seasons, respectively [3]. Climate change is therefore a threat to the Ethiopian economy and livelihoods of millions of the poor. The available option for Ethiopia to reduce the wideranging impacts of climate change is to adapt to changing climate. Generally, vulnerabilities are local and require location specific adaptation measures. Climate change vulnerability analyses for Ethiopia suggests that climate change over the coming decades presents a serious threat to various economic and social sectors. Addressing long-term climate change is thus required to reduce the impacts on livelihoods in general and major economic sectors such as agriculture, which is the mainstay of the country [4,5]. Ethiopia is expected to be hardest hit by climate change and the most vulnerable sectors are agriculture, water resources and human health. It is predicted that climate change could lead to increased water stress, overall reduction in agricultural productivity and yields, and expansion of vector habitats (spatial ecology) of diseases such as malaria. Climate change can significantly reverse the progress towards poverty reduction and food security in Ethiopia. Analyzing and assessing the spatio-temporal climate variability trends would help better understand impacts of climate change to formulate better strategies for climate change adaptation and mitigation in Ethiopia and encourage local proactive community participation and national efforts as a contribution to global climate change mitigation [6,7].

The climate of a location is affected by its latitude, terrain, and altitude, as well as nearby water bodies and their currents and inherent to climate are changes, both long-term and short-term [8-11]. Ethiopia shows a broadly consistent warming trend, with observations of increasing minimum and maximum temperatures over the past fifty years [12]. Proactive approaches to managing climate risks within vulnerable rural communities and among institutions operating at community, sub-national, and national levels is a crucial step toward achieving the sustainable economic development [3]. Climate change can significantly reverse the progress towards poverty reduction and food security in Africa [6]. NAPA process is confirming that sustainable land management, drought and agriculture are priority adaptation issues. These comprises increasing water storage facilities, improving water management, diversifying crops, developing irrigation systems, enhancing erosion control, improving and changing crop practices and management, improving pasture and livestock 
Page 2 of 7

management, increasing sustainable tree and forest products, and conserving forest ecosystems, genetic stocks and wildlife resources etc.,

Comparison of drought and famine periods with that of El Nino Southern Oscillation (ELSO) events showed a remarkable association, suggesting that the country is vulnerable to occurrences of El Nino and El Nina and associated climatic variations. Some droughts coincided while some others just followed the El Nino and El Nina events [2]. Experiences from elsewhere such as in China have shown that appropriate use and management of natural resources could enhance resilience of ecosystems and improve livelihoods of the poor in the face of climate change. The Ethiopian National Adaptation Program of Action (NAPA) also recognizes the importance of integrated natural resources management as an adaptation measure, where "Integrated Community- based watershed Management (ICBWSM)" is listed as one out of the 20 selected high priority adaptation projects $[2,13,14]$. Wing H. Cheung, et al. analyzed trends and spatial distribution of annual and seasonal rainfall in Ethiopia and found out a significant decline in June to September rainfall ('Kiremt') for the Baro-Akobo, Omo-Ghibe, Rift Valley, and Southern Blue Nile watersheds located in the southwestern and central parts of Ethiopia [9].

This article deals with application of geospatial techniques for climate change detection in Ethiopia for the period of 1946 to 2006; case study of point data analysis of semi-arid environment of Ethiopia (Mekelle station) for the period of 1980 to 2010 to detect and describe spatio-temporal trends and changes occurred during the study period; and assessment of SLM practices and their impacts on environmental rehabilitation, livelihoods, agricultural production, and contribution of SLM to climate mitigation.

\section{Materials and Methods}

\section{Data acquisition}

Data (1980-2010) from semi-arid Ethiopia (Mekelle station): The data set included maximum temperature for the hot season (AprilJune), minimum temperature for the cold season (October- January) and annual rainfall for the period of 1980-2010.

Climate research unit (CRU) dataset: Raster climate data including maximum temperature for warm season (April-June), cold season (October-January) and rainfall for the rainy season (June-September) for the years 1946 and 2006 were extracted from CRU Geospatial Raster Data Portal for Ethiopia to detect climate change in 60 years' time period. 60 years period was assumed to be reasonable time span to detect climate change based on data availability to the Ethiopian context. The CGIAR Consortium for Spatial Information (CGIAR-CSI) provides an-easy-to-use CRU TS 2.1 Global Climate Data for the entire world. The data has been produced by the CRU of University of East Anglia (UEA), and reformatted by International Water Management Institute (IWMI) to provide for easy access and to use in geospatial analysis using common GIS software. The CRU TS 2.1 Global Climate Dataset is comprised of 1224 monthly time-series of climate variables, for the period 1901-2002, covering the global land surface, excluding Antarctica, at 0.5 degrees resolution. The nine climate variables available through this dataset are: daily mean, minimum and maximum temperature, diurnal temperature range, precipitation, wet day frequency, frost day frequency, vapor pressure and cloud cover. The CRU is a component of the University of East Anglia, UK, and is one of the leading institutions concerned with the study of natural and anthropogenic climate change.

\section{Data processing and analysis}

Geospatial operations: Stacking, Spatial Analysis, Map calculation, overlaying and change detection were executed in ENVI 4.7 and ARC GIS 10 to generate spatiotemporal climate change difference maps for the indicated 60 years. The procedure of data extraction and stacking and analysis included:

Extraction (ARCGIS 10): Extraction through spatial masking to clip global data to Ethiopia;

Stacking: Stacking monthly data of a single parameter for the years 1946 and 2006 for further manipulation and analysis and Spatial Analysis, map calculation, union and difference mapping: Raster calculator, map algebra/map calculation and difference map for climate variability.

Climate variation (1946-2006): Difference map (GIS overlaying and subtraction techniques) was calculated as: Raster calculator (Subtraction): [2006]-[1946].

\section{Statistical analysis}

Descriptive statistics: It was applied to summarize data with measure of central tendency and measure of variability or dispersion (standard deviation and variance), the minimum and maximum variables. Descriptive summary was prepared for each parameter. Coefficient of variation (C.V.) was reported as a percentage value for each parameter. The variability of climate variables over the study period was examined by calculating coefficient of variation $(\mathrm{CV})$.

Time series trend analysis (parametric and non- parametric tests): This test is the result of the development of the nonparametric trend test first proposed by Mann-Kendall (1945) and has advantage of nonparametric robustness against departures from normality. We applied both trend analysis methods to explore temporal trend of climate and production variables. Non Parametric time series Mann Kendall trend test is adopted for testing temporal trend of climate variables as recommended by WMO [15-17]. We followed monotonic trend test in our study with both parametric and non-parametric trend (Mann Kendall) tests. Softwares used included ARC GIS 10, Excel and SPSS.

\section{Results and Discussion}

Parameter values as compared to pixel values:

Temperature and rainfall of pixel value is calculated by dividing each pixel value by 10 and the actual values of parameters are the figures indicated in each map divided by 10 (e.g. the value of rainfall appearing in the map is 12750 the actual rainfall would be $1275 \mathrm{~mm}$ and the same applies for temperature. Temperature of 183 in the map legend would mean the actual temperature is $18.3^{\circ} \mathrm{C}$ ).

\section{Spatiotemporal climate change, Ethiopia (1946-2006)}

Rainfall: 1946 monthly rainfall (June-September) shows that August received the highest rainfall $(580 \mathrm{~mm})$, July $(448 \mathrm{~mm})$ followed by September $(398 \mathrm{~mm}$ ) and June $(369 \mathrm{~mm}) .2006$ monthly rainfall shows August received $366 \mathrm{~mm}$, July $441 \mathrm{~mm}$, September $(255 \mathrm{~mm})$ and June $(294 \mathrm{~mm})$. There was a clear shift of monthly intensity of rainfall from 1946 to 2006. In 1946 the pick rainy month was August but in 2006 it was shifted to July. Likewise, in 1946 June received the least amount of rainfall but in 2006 it increased in amount and replaced September where September received the least rainfall amount in 2006. The 
Page 3 of 7

intensity of rainfall of September in 1946 and 2006 is shown in Figure 1.

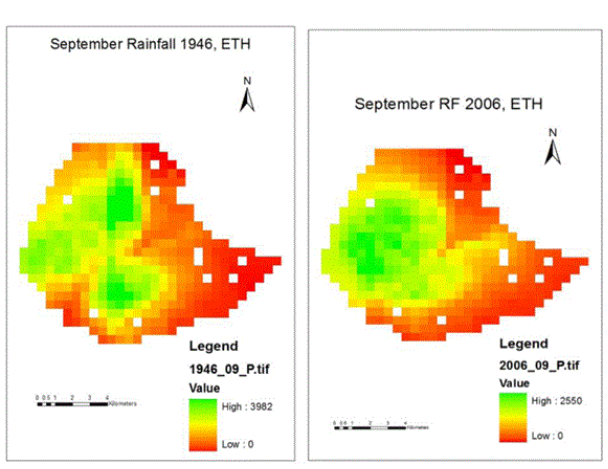

Figure 1: Rainfall intensity of September in 1946 and 2006.

Seasonal rainfall (June to September) was generated through raster calculator (addition) of monthly rainfall June through September for both 1946 and 2006. Rainfall change during 1946 to 2006 was calculated as the difference between 1946 and 2006 seasonal rainfall and it is simply directional trend between the two time periods as shown in Figure 2.

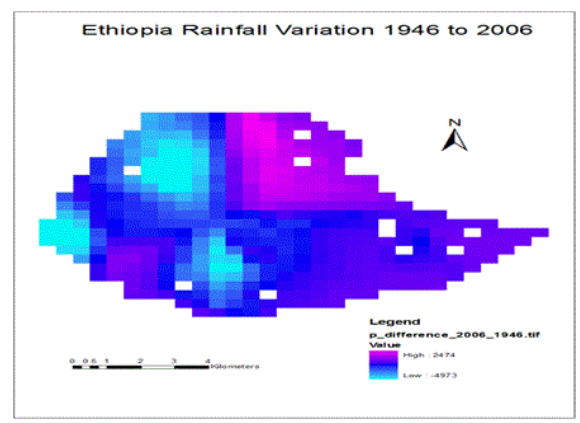

Figure 2: Seasonal rainfall change/difference between 1946 and 2006.

Rainfall generally show declining trend from periods 1946 to 2006. Moist areas of Western and South Western Ethiopia are showing negative (downward) trend of rainfall which indicates that their forest covers have been deteriorating through time. However, the drier Northern Ethiopia region area shows positive (upward) trends owing to massive environmental rehabilitation and restoration of degraded lands into productive lands in the last 25 years. The Public investment in Northern Ethiopia region on environmental rehabilitation has resulted in rehabilitated environment and contributed to reversing adverse effects of climate change as adaptation and mitigation strategies to global warming should be encouraged, globally recognized and rewarded.

Most of Ethiopia experiences one main wet season (called 'Kiremt') from mid-June to mid-September (up to $350 \mathrm{~mm}$ per month in the wettest regions), when the ITCZ is at its northern-most position. Parts of northern and central Ethiopia also have a secondary wet season of sporadic, and considerably lesser, rainfall from February to May (called the 'Belg'). The Southern regions of Ethiopia experience two distinct wet seasons which occur as the ITCZ passes through this more southern position The March to May 'Belg' season is the main rainfall season yielding $100-200 \mathrm{~mm}$ per month, followed by a lesser rainfall season in October to December called 'Bega' (around $100 \mathrm{~mm}$ per month). The eastern most corner of Ethiopia receives very little rainfall at any time of year.

The movements of the ITCZ are sensitive to variations in Indian Ocean sea-surface temperatures and vary from year to year, hence the onset and duration of the rainfall seasons vary considerably interannually, causing frequent drought. The most well documented cause of this variability is the El Niño Southern Oscillation (ENSO). Warm phases of ENSO (El Niño) have been associated with reduced rainfall in the main wet season, JAS, in north and central Ethiopia causing severe drought and famine, but also with enhanced rainfalls in the earlier February to April rainfall season which mainly affects southern Ethiopia (Figure 3).

Studies by UNDP and NASA show similar results of rainfall fluctuation in Ethiopia. The strong inter-annual and inter-decadal variability in Ethiopia's rainfall makes it difficult to detect long-term trends. There is not a statistically significant trend in observed mean rainfall in any season in Ethiopia between 1960 and 2006. Decreases in JAS rainfall observed in the 1980s have shown recovery in the 1990s and 2000s (UNDP Portal). Study by NASA [18] has identified a link between a warming Indian Ocean and less rainfall in eastern and southern Africa. Computer models and observations show a decline in rainfall, with implications for the region's food security. Rainfall in eastern Africa during the rainy season, which runs from March through May, has declined about 15 percent since the 1980s, according to records from ground stations and satellites. Statistical analyses show that this decline is due to irregularities in the transport of moisture between the ocean and land, brought about by rising Indian Ocean temperatures.

Maximum temperature variation (April- June, 1946-2006)

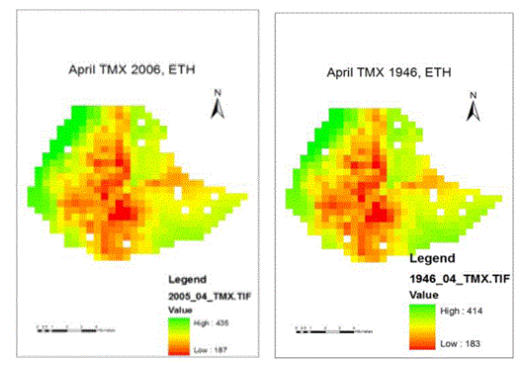

Figure 3: Maximum temperature April 1946 and 2006.

Maximum temperature for the months April through June for both 1946 and 2006 was computed with same procedure for rainfall and changes in monthly maximum temperature are detected for each month. Maximum temperature of April increased by $2.3^{\circ} \mathrm{C}$ during the period of 1946 to 2006 (Figures 4 and 5). 
Citation: Abbadi GR (2016) Evidences of Spatiotemporal Climate Change and its Mitigation in Ethiopia. Hydrol Current Res 7: 220. doi:

Page 4 of 7

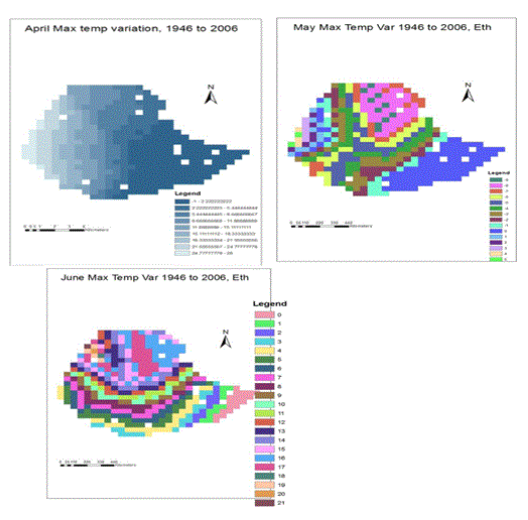

Figure 4: Maximum temperature variation for April, May and June (1946-2006).

Minimum temperature variation (October- January, 1946-2006)
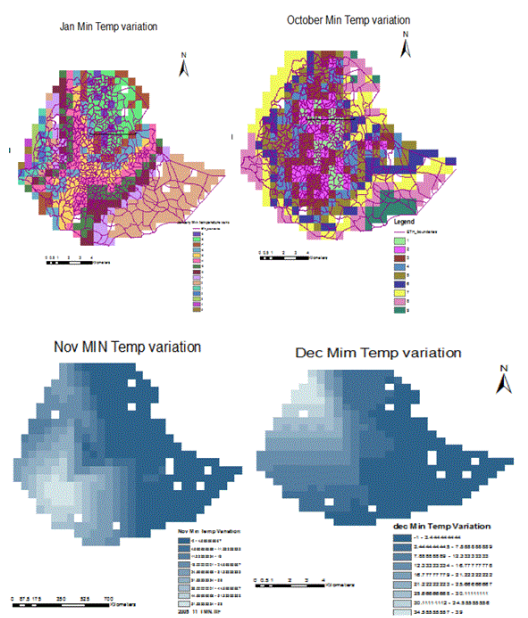

Figure 5: Minimum temperature variation (October-January, 1946-2006).

Minimum temperature shows two extreme facts. In some areas it is falling down than before indicating that they are becoming cooler than before. In other areas, minimum temperature is rising up that places that were very cold are decreasing their coldness. These data are in support of Ethiopian Meteorological Agency records. These data are evidence of global climate change for the existence of extreme weather changes justifying that some areas unusually are becoming cold and some becoming warmer and hotter than before because of global warming.

Over the last five decades frequency of occurrence of extreme weather events such as drought and flood show an increasing trend. Particularly since the 1980s, droughts of various intensities have occurred every 4 or 5 years and seem to be more frequent since 1997. Seasonal and inter-annual rainfall variability has increased and temperature shows an increasing trend. The spatial and temporal distribution of the available water resources is however highly uneven as driven by the variable climate [2]. Mean annual temperature has increased by $1.3^{\circ} \mathrm{C}$ between 1960 and 2006 , an average rate of $0.28^{\circ} \mathrm{C}$ per decade. The increase in temperature in Ethiopia has been most rapid in JAS at a rate of $0.32^{\circ} \mathrm{C}$ per decade. Daily temperature observations show significantly increasing trends in the frequency of hot days, and much large increasing trends in the frequency of hot nights (UNDP country portal) (Figure 6).

\section{Case study: Temporal climate variation of point data (Mekelle station, 1980-2010)}

Temporal climate trend

\begin{tabular}{|c|c|c|c|c|c|}
\hline Variable & $\mathbf{R}^{2}$ & $\begin{array}{l}\text { Standard } \\
\text { error }\end{array}$ & $\mathbf{F}$ & $\begin{array}{l}\mathrm{P} \text { - } \\
\text { value }\end{array}$ & Trend \\
\hline \multicolumn{6}{|c|}{ Maximum temperature $\left({ }^{\circ} \mathrm{C}\right)$} \\
\hline April & 0.003 & 0.07 & 0.102 & 0.75 & $\begin{array}{l}\text { NS (No significant } \\
\text { trend) }\end{array}$ \\
\hline May & 0.052 & 0.02 & 1.2 & 0.29 & $\begin{array}{l}\text { NS (No significant } \\
\text { trend) }\end{array}$ \\
\hline June & $\begin{array}{l}0.000 \\
5\end{array}$ & 0.025 & 0.029 & 0.87 & $\begin{array}{l}\text { NS (No significant } \\
\text { trend) }\end{array}$ \\
\hline \multicolumn{6}{|c|}{ Minimum temperature $\left({ }^{\circ} \mathrm{C}\right)$} \\
\hline October & 0.26 & 0.021 & 9.6 & 0.005 & Significant trend \\
\hline November & 0.21 & 0.029 & 7.1 & 0.014 & Significant trend \\
\hline December & 0.21 & 0.03 & 6.5 & 0.018 & Significant trend \\
\hline January & 0.22 & 0.03 & 6.4 & 0.019 & Significant trend \\
\hline $\begin{array}{l}\text { Annual } \\
\text { rainfall }(\mathrm{mm})\end{array}$ & 0.154 & 2.1 & 4.2 & 0.052 & $\begin{array}{l}\text { NS (No significant } \\
\text { trend) }\end{array}$ \\
\hline
\end{tabular}

Table 1: Temporal trend of climate variables at Mekelle (1980-2010).

Minimum temperature (October-January) showed significant trend while maximum temperature and rainfall had no significant trend during 1980-2010 period based on XLSTAT 2012 parametric and nonparametric trend tests. Results combine trend tests show similar trends and hence maximum temperature and rainfall had no significant trend.

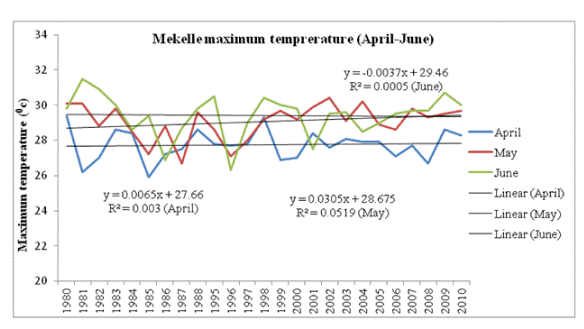

Figure 6: Maximum temperature trend (Mekelle, 1980-2010). 
Page 5 of 7

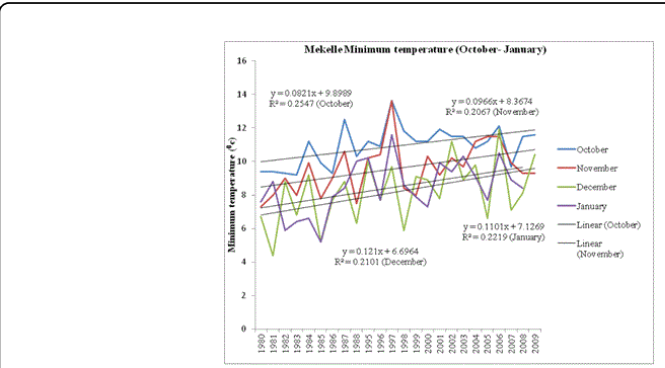

Figure 7: Minimum temperature trend (Mekelle,1980-2010).

\begin{tabular}{|c|c|c|c|c|c|c|c|c|}
\hline \multirow{2}{*}{$\begin{array}{l}\text { Statistic } \\
\text { s }\end{array}$} & \multicolumn{3}{|c|}{$\begin{array}{l}\text { Maximum temperature } \\
\left({ }^{\circ} \mathrm{C}\right)\end{array}$} & \multicolumn{4}{|c|}{ Minimum temperature $\left({ }^{\circ} \mathrm{C}\right)$} & \multirow[t]{2}{*}{$\begin{array}{l}\text { Annua } \\
\text { rainfal } \\
(\mathrm{mm})\end{array}$} \\
\hline & April & May & June & Oct & Nov & Dec & Jan & \\
\hline Mean & 27.74 & 29.07 & 29.41 & $\begin{array}{l}10.9 \\
3\end{array}$ & 9.58 & 8.21 & 8.48 & 482 \\
\hline Max & 29.4 & 30.1 & 31.5 & 13.6 & 13.6 & 11.9 & 11.6 & 710 \\
\hline Min & 25.9 & 26.7 & 26.9 & 9.2 & 7.3 & 4.4 & 5.2 & 230 \\
\hline S.D & 0.87 & 0.99 & 1.19 & 1.15 & 1.5 & 1.87 & 1.56 & 116 \\
\hline C.V & 0.03 & 0.03 & 0.04 & 0.11 & 0.16 & 0.23 & 0.18 & 0.24 \\
\hline C.V (\%) & 3 & 3 & 4 & 11 & 16 & 23 & 18 & 24 \\
\hline
\end{tabular}

Table 2: Descriptive statistics of climate variables at Mekelle station (1980-2010).

Minimum temperature (October-January) was highly variable with coefficient of variation ranging $11 \%$ to $23 \%$ whereas maximum temperature was stable with minimum variation during the period of 1980 to 2010 (Table 2). Minimum temperature (October-January) showed significant increasing trend while maximum temperature and rainfall had no significant trend during 1980-2010 period (Table1, Figure 7). Minimum temperature of October had the highest increasing rate of $0.026^{\circ} \mathrm{C} / \mathrm{annum}$. This increasing trend of minimum shows those seasons are getting hotter in recent years. This is also in line with global climate change and variability trends that some places are getting hotter in which cold periods of the year are getting hotter. This variability is manifested either by rise of maximum temperatures or increment of minimum temperatures so that years and seasons become hotter than their past climatic condition. Rainfall was characterized by high inter-annual variability. June 1981 was the warmest month with highest maximum temperature of $31.5^{\circ} \mathrm{C}$ while December 1981 was the coldest month with minimum temperature of $4.4^{\circ} \mathrm{C}$ indicating that the year 1981 had the warmest month in June and the coldest month in December. This year had highest record of maximum temperature and lowest record of minimum temperature. Years 1980, 2001 and 2006 were relatively wet years while year 1984 was the driest year manifested by the worst 1984 drought in Northern Ethiopia comparative results of Mekelle area have also been obtained from World Weather information Service (WWIS). Maximum temperature for the warm season of April to June shows some increasing and decreasing trend for the month of April in some areas. There is increasing trend in May but very distinct increment in June which is in agreement with other studies (FAO, UNDP and IPCC).
Minimum temperature of the cold season (October-January) is rising up.

\section{SLM for climate change mitigation in Ethiopia}

An option for adaptation to climate change and necessary condition for sustainable agriculture in itself is sustainable land management (SLM) and rehabilitation of degraded lands. Community Based Integrated Watershed Management (CBIWSM) approach was adopted as one of the top climate change adaptation strategies in Ethiopia. Massive sustainable local community based natural resource management efforts have been undertaken to reverse this situation and there are a lot of success stories in the last 25 years which includes: Water harvesting, Irrigation (crop diversification and intensification), Zero grazing, A (re)forestation, plantation, agroforestry, closure areas, protected forests, intensive and integrated watershed management approach/ SWC and conservation agriculture. Land degradation is primed to exacerbate climate change impacts. Conversely, SLM practices constitute key adaptation measures by resulting in reduced soil erosion, improved water retention, and improved land productivity. Sustainable Land Management (SLM) requires addressing of the underlying causes to land degradation. Environmental rehabilitation efforts in Ethiopia have brought about reclamation of waste lands, re-vegetation of degraded hillsides, restoration of damaged pasturelands, and adoption of improved soil and water conservation and management technologies in cultivated lands. SLM practices and climate change adaptation and mitigation strategies are mutually supportive and represent win-win options. The causes of land degradation in Ethiopia are complex and diverse. These include natural factors such as the rugged terrain, erosive rainfall and inherently fragile soils, and a number of immediate and underlying causes. The immediate causes relate to unsuitable land uses and inappropriate farming and livestock management practices, while the underlying causes relate to the more fundamental issues of land users' circumstances such as scarcity of resources, security of tenure over resources, poverty, and functioning policies and institutions, Sustainable Land Management (SLM) requires addressing of the underlying causes to the problem [1]. It is a multi-sectoral and multistakeholder program that brings communities, the government and the supporting institutions on common platform and towards shared results. The overall objective of SLM Program is to improve the livelihood of land users and communities through implementation of SLM activities in the framework of community-based participatory watershed development plans (Table 3).

\begin{tabular}{|l|l|l|l|}
\hline S.N. & Activities & Unit & Total \\
\hline 1 & Farm bunds & $\mathrm{Ha}$ & $21,40,898$ \\
\hline 2 & Hillside bunds & $\mathrm{Ha}$ & $12,92,164$ \\
\hline 3 & Terracing & $\mathrm{KM}$ & 72,104 \\
\hline 4 & Micro basin & $\mathrm{No}$ & $4,04,00,000$ \\
\hline 5 & Cut-off drains & $\mathrm{KM}$ & 11,265 \\
\hline 6 & Drainage/diversion channel & $\mathrm{KM}$ & 3,772 \\
\hline 7 & Area closure & $\mathrm{Ha}$ & $3,98,000$ \\
\hline 8 & Seedling raising & $\mathrm{No}$ & $2,50,00,00,000$ \\
\hline 9 & Plantation & $\mathrm{Ha}$ & $9,18,000$ \\
\hline
\end{tabular}


Page 6 of 7

\begin{tabular}{|l|l|l|l|}
\hline 10 & Micro dam & No & 133 \\
\hline 11 & River diversion & No & 4,166 \\
\hline 12 & Pond construction & No & 1,988 \\
\hline 13 & Stream development & No & $1,09,642$ \\
\hline
\end{tabular}

Table 3: Land rehabilitation activities in Ethiopia (1979-1990).

\begin{tabular}{|l|l|l|l|l|l|l|}
\hline \multirow{2}{*}{ Year } & \multirow{2}{*}{$\begin{array}{l}\text { Area } \\
(\mathrm{Ha})\end{array}$} & \multirow{2}{*}{$\begin{array}{l}\text { Production } \\
(\mathbf{Q t})\end{array}$} & \multicolumn{4}{l}{ Beneficiaries } \\
\cline { 5 - 7 } & & Male & Female & Youth & Total \\
\hline 2003 & 4773 & 673580 & 20982 & 6445 & - & 27427 \\
\hline 2004 & 11673 & 1023722 & 40689 & 12500 & - & 53189 \\
\hline 2005 & 15645 & 1361115 & 88821 & 27285 & - & 116106 \\
\hline 2006 & 17429 & 1516323 & 121781 & 37514 & - & 151551 \\
\hline 2007 & 29734 & 1878853 & 199430 & 59570 & - & 196000 \\
\hline 2008 & 38120 & 2766249 & 164422 & 47578 & - & 212766 \\
\hline 2009 & 40845 & $52,00,000$ & 191740 & 47935 & - & 239675 \\
\hline 2010 & 83000 & $55,00,000$ & 210000 & 59000 & - & 269000 \\
\hline 2011 & 125558 & $1,80,58,897$ & 283059 & 94679 & 44977 & 419689 \\
\hline 2012 & 154854 & $2,12,61,665$ & 279960 & 100576 & 98769 & 479305 \\
\hline 2013 & 214865 & $2,85,54,866$ & 301415 & 120415 & 124204 & 546146 \\
\hline
\end{tabular}

Table 4: Expansion of irrigation agriculture in Tigray region as a result of SLM practices.

Overall impacts of environmental rehabilitation in Ethiopia include:

- Reclamation of gully and degraded lands in to productive lands

- Enhanced surface and ground water availability

- Modification of microclimates

- Increased productivity

- Soil fertility and moisture availability enhanced use of chemical fertilizers

- Environmental, ecological, habitat and biodiversity rehabilitation/ restoration

- Feed and water availability for livestock

- Overall impacts on household incomes and livelihood outcomes, and

- Enhanced resilience to adverse effects of climate change (Table 4)

Mitigation of climate change refers to interventions aimed at reducing emissions from the sources or enhancing the sinks of Green House Gases (GHG). SLM, in addition to its role in adaptation, provides a significant potential as a mitigation measure. Globally, agriculture and land use changes are major contributors of GHGs [8]. This means, in other words, appropriate agricultural practices and land use and land cover management offers a great mitigation potential. Sustainable forest management, reducing emissions from deforestation and forest degradation (REDD) is one of the recognized mitigation options. Soil carbon sequestration also has a huge mitigation potential with a wide-range of synergies such as improved productivity and soil health [1]. Agriculture and SLM are important domains through which

developing countries can contribute to global mitigation efforts as they fall within National Appropriate Mitigation Actions (NAMAs). Environmental rehabilitation efforts in Ethiopia have brought about reclamation of waste lands, re-vegetation of degraded hillsides, restoration of damaged pasturelands, and adoption of improved soil and water conservation and management technologies in cultivated lands. In consequence, these efforts have apparently led to enhanced carbon sequestration and both above-and below-ground carbon stocks. SLM practices and climate change adaptation and mitigation strategies are mutually supportive and represent win-win options.

\section{Conclusion and Recommendation}

The Ethiopian climate has shown a drastic spatiotemporal climate change in the last 60 years (1946-2006) which manifests the impact of global warming at local level. The strong inter-annual and interdecadal variability in Ethiopia's rainfall makes it difficult to detect long-term trends. Rainfall trend through 1946 to 2006 for moist areas of Western and South Western Ethiopia are showing downward (negative) trend of rainfall which indicates that their forest covers have been deteriorating through time. However, interestingly, the Northern Ethiopian region shows positive (upward) trends owing to massive environmental rehabilitation and restoration of degraded lands into productive lands in the last 25 years. There was an increasing trend of both maximum and minimum temperature while there was no consistency in rainfall patterns. Our findings are in line with global trends of temperature and rainfall changing patterns. CRU is one of the huge climate resource data center with its raster global climate data portal for the period of 1901 to 2006. GIS has efficient tools to extract, manipulate and analyse global data in to area of interest and generate spatial data within short time.

The Public investment in Northern Ethiopia region on environmental rehabilitation has resulted in rehabilitated environment, improved livelihoods, and contributed to reversing adverse effects of climate change as adaptation and mitigation strategies to global warming should be encouraged, globally recognized and rewarded. Detailed agroclimate based analysis is required to generate high spatial resolution outputs with locally specific application for climate change assessment and design effective adaptation strategies in the face of climate change. Synergy is needed to complement local climatological knowledge and build capacity of community for Early Warning System at local level to better utilize (exploit) climatological potentials and minimize risks due to natural disasters. The results of this study will serve as a milestone for further detailed analysis and impact assessment studies.

The Kyoto period is the lost opportunity for Africa. Ethiopia as one of the hardest hit countries by global climate change has developed climate change adaptation and mitigation strategies (NAPA and NAMA) and has mobilized its resources and implements different projects. This effort is also development pathway for Ethiopia. This lead national effort in Africa should be appreciated and be supported by international initiatives such as UN-based frameworks.

\section{References}

1. WoldeAmlak Bewuket (2009) Environmental rehabilitation in response to climate change in Ethiopia. WFP, MERET Project Evaluation Report, Ethiopia.

2. NMSA (2008) Climate change adaptation task force and plans. 
Citation: Abbadi GR (2016) Evidences of Spatiotemporal Climate Change and its Mitigation in Ethiopia. Hydrol Current Res 7: 220. doi: 10.4172/2157-7587.1000220

Page 7 of 7

3. Temesgen Deressa, Rashid M. Hassan Claudia Ringler (2007) Measuring Ethiopian Farmers' Vulnerability to Climate Change Across Regional States. IFPRI Discussion Paper.

4. Arndt C, Ahmed H, Sherman Robinson, Willenbekel D (2009) Climate change and Ethiopia. Earth and Environmental Sciences 6.

5. GEF (2006) Ethiopia: Coping with drought and climate change.

6. FAO (2007) Adaption to climate change in agriculture, forestry and fisheries: Perspectives, frameworks and Priorities.

7. FAO (2010) Climate change threat to Africa: Adaptation a priority.

8. IPCC WG (2007) IPCC Fourth Assessment Report: Climate Change(AR4).

9. Wing H Cheung, Gabriel B Senay, Ashbindu Singh (2008) Trends and Spatial Distribution of Annual and Seasonal Rain fall in Ethiopia. International Journal of Climatology 28: 1723-1734.

10. Abbadi Girmay Reda and Nitin K Tripathi (2010) Climate change adaptation through environmental rehabilitation in Ethiopia.In: Nitin K
Tripathi (Ed.) ISBN: 978-616-90698-0-5. Proceedings of third International Conference on Geoinformation Technology for Natural Disaster Management Thailand. pp. 9-13.

11. Abbadi Girmay Reda, Nitin K Tripathi (2011) Mainstreaming Climate Change Adaptation in Urban Planning in Africa. In USMCA 2011 International Symposium, Thailand.

12. McSweemy (2010) UNDP Climate Change Country Profiles.

13. IFPRI (2010) Climate Change impacts in Ethiopia and South Africa.

14. FDRE (2008) Ethiopia Country reports.

15. WMO (1996) Standard climatological year of 1961-90.

16. WMO (2009) Addressing climate information needs at the regional level.

17. IPCC (1994) Technical Guidelines for Assessing Climate Change Impacts and Adaptations with a Summary for Policy Makers and a Technical Summary.

18. NASA (2012) Recent drought and precipitation tendencies in Ethiopia. 